\title{
A hybrid zone between two subspecies of the grasshopper Chorthippus parallelus along the Pyrenees: the west end
}

\author{
I. BUÑO*, E. TORROJA†, C. LÓPEZ-FERNÁNDEZ, R. K. BUTLIN ‡, G. M. HEWITT§ \\ \& J. GOSÁLVEZ \\ Unidad de Genética, Departamento de Biologia, Facultad de Ciencias, Universidad Autónoma de Madrid, 28049 Madrid, \\ Spain, $\uparrow$ Centro de Investigaciones Biológicas, Consejo Superior de Investigaciones Científicas (CS/C), Madrid, Spain, \\ $\ddagger$ Department of Genetics, University of Leeds, Leeds LS2 9JT, UK and \$School of Biological Sciences, University of
}

East Anglia, Norwich NR4 7TJ, UK

\begin{abstract}
The grasshopper Chorthippus parallelus $(C p)$ has two distinct subspecies which meet along the Pyrenees forming a hybrid zone. As $C p$ is rarely found above $2000 \mathrm{~m}$, the contact between the two subspecies must occur through valleys crossing the Pyrenees perpendicularly or at both ends of the mountain ridge. The contact zones in two valleys have already been studied in detail, Col de Portalet (Central Pyrenees) and Col de la Quillane (Eastern Pyrenees), and this paper analyses the structure of the contact zone at the western end of the Pyrenees. The study has been carried out using different chromosome markers obtained by $\mathrm{C}$-banding and silver staining, both related to the sex chromosome. Although the structure of this contact zone, analysed using these two markers, is similar to that of the contact zones occurring in other valleys, it is much wider and some remarkable peculiarities in the shapes of the clines have been detected. Additionally, hybrid-related sex chromosome markers detected in Portalet have not been found in the present sample.
\end{abstract}

Keywords: Chorthippus, evolution, hybrid zones, insect cytogenetics, Orthoptera, speciation.

\section{Introduction}

\section{The hybrid zone}

The meadow grasshopper Chorthippus parallelus (Orthoptera: Acrididae) $(C p)$ is widely distributed through Europe. The colour of the hind tibiae in particular allowed Faber (1958) to distinguish two subspecies, $C p$ parallelus (Cpp) and Cp erythropus (Cpe). $C p e$ is endemic in the Iberian Peninsula whereas $C p p$ is the form that has been described in the rest of Europe. During the last Ice Age the Pyrenees were covered by ice and $C p$ retreated south into Spain, Italy and the Balkans. At this stage, as in previous ice ages, isolated refugial populations would have diverged in allopatry. As the climate warmed in the postglacial period the two races expanded northwards from their refugia and made secondary contact along the Pyrenees. Both races mated, hybridized, as indeed they still do, and thereby formed a hybrid zone (HZ) (Hewitt, 1989).

*Correspondence.
The two subspecies differ in the number of pegs in the stridulatory row (Reynolds, 1980), in several other morphological characters (Butlin \& Hewitt, 1985a), in certain enzyme loci (Butlin \& Hewitt, 1985a), in the use and structure of acoustic signals (Butlin \& Hewitt, 1985b), in their mating behaviour (Ritchie et al., 1989, 1992; Ritchie, 1990) and in some genome traits (Gosálvez et al., 1988; Bella et al., 1990, 1992, 1993). There are clines of all these characters across the $\mathrm{HZ}$ (Hewitt et al., 1988; Hewitt, 1993).

$C p$ is rarely found above $2000 \mathrm{~m}$ and so contact between the two subspecies must occur through high valleys crossing the ridge of the Pyrenees, or at both ends of the mountain chain. Two such high cols, Col de Portalet (Central Pyrenees) and Col de la Quillane (Eastern Pyrenees), in which geographical features reduce the habitable territory for these grasshoppers to narrow corridors, have been studied in some detail (for review see Hewitt, 1990, 1993). However, detailed information on the contact zones at the west and east ends of the Pyrenees has not been available up until now. This paper reports a study of the $\mathrm{HZ}$ at its western end. For this purpose, 33 localities within an area 
some $15000 \mathrm{~km}^{2}$ have been sampled for 2 consecutive years.

\section{Chromosome markers to study the hybrid zone}

Both subspecies have a similar chromosome complement of three pairs of long submetacentric chromosomes $\left(\mathrm{L}_{1}-\mathrm{L}_{3}\right)$, three medium-sized acrocentric pairs $\left(\mathrm{M}_{4}-\mathrm{M}_{6}\right)$, two small acrocentric pairs $\left\langle\mathrm{S}_{7}-\mathrm{S}_{8}\right)$ and the $\mathrm{X}$ chromosome (female XX, male $\mathrm{XO}$ ), which is as long as the longest medium sized pair and is also acrocentric (Gosálvez et al., 1988).

Using silver staining to locate active nucleolar organising regions (NORs), it was found that Cpp has three silver precipitates through the first meiotic prophase. These active regions are located interstitially and distally on the short arms of chromosomes $\mathrm{L}_{2}$ and $\mathrm{L}_{3}$, respectively, and distally on the sex chromosome. Cpe only shows the two autosomal NORs, thus lacking that on the $\mathrm{X}$ chromosome. This difference provides a clear chromosome marker to study the HZ (Gosálvez et al., 1988). Distinct clines for this character have been detected (Hewitt et al., 1988).

The sex chromosome shows a different C-banding pattern in the two subspecies (Gosálvez et al., 1988). The sex chromosome of Cpp has a positive C-band at the centromere and another at the distal end. The sex chromosome of Cpe also shows the centromeric band, while the distal band present in $C p p$ is replaced by an interstitial one.

Both NOR activity and sex chromosome C-bands are very good markers for the analysis of the distribution of pure populations and the regions where both subspecies meet and form hybrids. In this paper we analyse the configuration of the contact zone at the west end of the Pyrenees by using these two markers.

\section{Materials and methods}

Adult individuals of the meadow grasshopper $C p$ were sampled at 33 localities in the western Pyrenees (Figs 2 and 4, Table 1). As one of the main purposes of this investigation was to determinate the area of influence of our markers, no specific transects were considered and each population was randomly fixed on a map and sampled. In any case, the relatively smooth orography of this region (no peaks above $2000 \mathrm{~m}$ ) gives rise to a continuous distribution of populations in which predetermination of a transect is completely artificial.

Testes were removed fresh, fixed in 3:1 ethanolacetic acid and stored at $4^{\circ} \mathrm{C}$. Two to three testicular follicles were squashed in 45 per cent acetic acid solution and cover slips were removed with a razor blade after freezing in liquid nitrogen. The slides were airdried for at least $8 \mathrm{~h}$.
C-bands were obtained following Sumner (1972) with some minor modifications. The slides were treated with a 5 per cent solution of barium hydroxide at $60^{\circ} \mathrm{C}$ for $30 \mathrm{~min}$. The slides were first washed with tap water and then two to three drops of 45 per cent acetic acid solution were added before a second washing in tap water. The slides were then steeped in $2 \times$ SSC at $60^{\circ} \mathrm{C}$ for $30 \mathrm{~min}$, then rinsed with tap water for several minutes. Slides were stained with Giemsa ( 2 per cent) for $3 \mathrm{~min}$ and then mounted.

Silver staining was carried out according to Rufas \& Gosalvez (1982). Slides were incubated with a drop of a 50 per cent $\mathrm{AgNO}_{3}$ solution ( $\mathrm{pH} 3.5$ ) for 5 min at $60^{\circ} \mathrm{C}$, washed with distilled water and counterstained with 1 per cent solution of Giemsa before mounting.

Observations were carried out in a Zeiss Photo III microscope and photographs were taken with Kodak Plus X (in the case of silver staining) or Recordak (for C-banding) film.

\section{Results}

\section{C-bands}

C-bands from pure individuals do not show any differences in our samples other than those already found in populations from the Cols of Portalet and Quillane. Those differences found on autosomes constitute a polymorphic system involving both size and presence/ absence of distal heterochromatic supernumerary segments and affect similarly individuals of all populations. On the other hand, those which affect the sex chromosomes are diagnostic for pure individuals from each subspecies and can be used as chromosomal markers to study the structure of the contact zone. The sex chromosome of Cpp shows two heterochromatic bands, a centromeric one $(C)$ and a distal one $\left(\mathrm{P}_{2}\right)(\mathrm{Fig}$. 1a). The sex chromosome of Cpe also has a centromeric band $(\mathrm{C})$, which is indistinguishable from its counterpart in Cpp using this technique, and an interstitial band $\left(\mathrm{E}_{2}\right)$ (Fig. 1b). The sex chromosome of pure $C p p$ individuals consistently shows an invariable $\mathrm{CP}_{2}$ pattern whereas that of $C p e$ has a $\mathrm{CE}_{2}$ pattern. $\mathrm{A}$ population is considered to be pure, using these chromosome markers, when all the individuals show either $\mathrm{CP}_{2}$ or $\mathrm{CE}_{2} \mathrm{C}$-banding patterns. In addition to these sex chromosomes, two other $\mathrm{C}$-banding patterns have been found. One of them shows only the centromeric band $(\mathrm{C})$ and the other includes the three bands $\left(\mathrm{CE}_{2} \mathrm{P}_{2}\right)$ (Fig. 1c, d).

Roughly, pure populations showing the $\mathrm{CP}_{2} \mathrm{C}$-banding pattern were found to the north and the north-east of the studied area whereas $\mathrm{CE}_{2}$ pure populations occupy the south-west region (Fig. 2a). Between them, a wide range of hybrid populations was found. Within 
Table 1 Localities sampled at the western end contact zone. The number of individuals $(N)$ studied with each technique and the results obtained for the different chromosome markers expressed in percentages are shown

\begin{tabular}{|c|c|c|c|c|c|c|c|c|c|}
\hline Population & $N$ & $\mathrm{CP}_{2}$ & $\mathrm{CE}_{2}$ & C & $\mathrm{CE}_{2} \mathrm{P}_{2}$ & $\mathrm{P}_{2}$ & $E_{2}$ & $N$ & X-NOR \\
\hline ROI & 15 & 0 & 100 & 0 & 0 & 0 & 100 & 15 & 3.20 \\
\hline ARR & 15 & 0 & 100 & 0 & 0 & 0 & 100 & 15 & 3.66 \\
\hline ULZ & 16 & 0 & 100 & 0 & 0 & 0 & 100 & 16 & 13.95 \\
\hline VEL1 & 15 & 0 & 100 & 0 & 0 & 0 & 100 & 15 & 13.89 \\
\hline VEL2 & 15 & 0 & 40 & 20 & 40 & 40 & 80 & 17 & 10.16 \\
\hline BER & 15 & 27 & 0 & 47 & 27 & 54 & 27 & 15 & 19.78 \\
\hline ORO & 15 & 0 & 80 & 0 & 20 & 20 & 100 & 15 & 23.33 \\
\hline ART & 18 & 0 & 0 & 28 & 72 & 72 & 72 & 18 & 17.74 \\
\hline $\mathrm{ABO}$ & 15 & 73 & 0 & 27 & 0 & 73 & 0 & 15 & 30.29 \\
\hline ORB & 16 & 81 & 0 & 0 & 19 & 100 & 19 & 16 & 48.89 \\
\hline LAA5 & 18 & 100 & 0 & 0 & 0 & 100 & 0 & 20 & 41.45 \\
\hline ERR & 16 & 81 & 0 & 0 & 19 & 100 & 19 & 17 & 73.10 \\
\hline LAA4 & 15 & 20 & 20 & 40 & 20 & 40 & 40 & 18 & 19.92 \\
\hline IZP3 & 18 & 22 & 28 & 0 & 50 & 72 & 78 & 18 & 21.48 \\
\hline IZP4 & 16 & 69 & 0 & 31 & 0 & 69 & 0 & 16 & 11.26 \\
\hline LAA3 & 16 & 100 & 0 & 0 & 0 & 100 & 0 & 15 & 42.50 \\
\hline IZP2 & 18 & 50 & 0 & 50 & 0 & 50 & 0 & 16 & 39.17 \\
\hline IZP1 & 14 & 64 & 0 & 36 & 0 & 64 & 0 & 14 & 16.07 \\
\hline LAA2 & 15 & 66 & 0 & 0 & 33 & 100 & 33 & 16 & 34.93 \\
\hline LAR2 & 15 & 66 & 0 & 0 & 33 & 100 & 33 & 17 & 69.86 \\
\hline EST & 17 & 100 & 0 & 0 & 0 & 100 & 0 & 15 & 71.36 \\
\hline MAK & 15 & 47 & 27 & 27 & 0 & 47 & 27 & 15 & 31.21 \\
\hline LAR1 & 16 & 25 & 0 & 50 & 25 & 50 & 25 & 18 & 61.80 \\
\hline LIZ & 15 & 60 & 0 & 0 & 40 & 100 & 40 & 16 & 85.98 \\
\hline APH & 16 & 62 & 0 & 19 & 19 & 81 & 19 & 15 & 53.91 \\
\hline BEH & 14 & 86 & 14 & 0 & 0 & 86 & 14 & 21 & 49.38 \\
\hline ERE & 17 & 100 & 0 & 0 & 0 & 100 & 0 & 16 & 70.83 \\
\hline LAA1 & 16 & 100 & 0 & 0 & 0 & 100 & 0 & 18 & 93.02 \\
\hline ARZ & 16 & 75 & 0 & 25 & 0 & 75 & 0 & 15 & 61.25 \\
\hline HOS & 19 & 100 & 0 & 0 & 0 & 100 & 0 & 18 & 41.15 \\
\hline MAU & 20 & 100 & 0 & 0 & 0 & 100 & 0 & 20 & 85.80 \\
\hline LOU & 18 & 100 & 0 & 0 & 0 & 100 & 0 & 16 & 95.80 \\
\hline PRE & 19 & 100 & 0 & 0 & 0 & 100 & 0 & 20 & 99.40 \\
\hline
\end{tabular}

the $\mathrm{HZ}$ we may identify $\mathrm{CP}_{2}$ and $\mathrm{CE}_{2}$ sex chromosomes in addition to the expected recombinants, i.e. $\mathrm{C}$ and $\mathrm{CE}_{2} \mathrm{P}_{2}$ (Fig. 1). Frequencies of each type are summarized in Table 1. Although we know for certain that $\mathrm{C}$ and $\mathrm{CE}_{2} \mathrm{P}_{2}$ are hybrid products of recombination, $\mathrm{CP}_{2}$ and $\mathrm{CE}_{2}$ may also harbour hybrid genome conformations not detectable using these bands as markers. For this reason $\mathrm{E}_{2}$ and $\mathrm{P}_{2}$ bands were considered as independent markers, irrespective of the overall C-banding pattern observed on the sex chromosomes. Frequencies are shown in Table 1.

The gradual transition from one pure set to the other allows clines to be plotted for these two bands (Fig. 2b). To reduce the two-dimensional data to a linear transect, the Buño et al. (unpublished) model for multidirectional sampling was performed. This simple model involves arranging the populations according to their relative distances from a reference line. From the infinite number of reference lines that can be generated (differing from each other in the angle they form with a horizontal line) only one gives the best arrangement of populations to obtain clear clines. Maximum likelihood estimates of the parameters of a tanh curve were obtained using the nonlinear regression facilities of GENSTAT (GENSTAT 5, 1987). The centre and width estimates obtained for the different clines are shown in Table 2 for both the complete data set and the limited area of more intensive sampling marked in Fig. 2(a). 


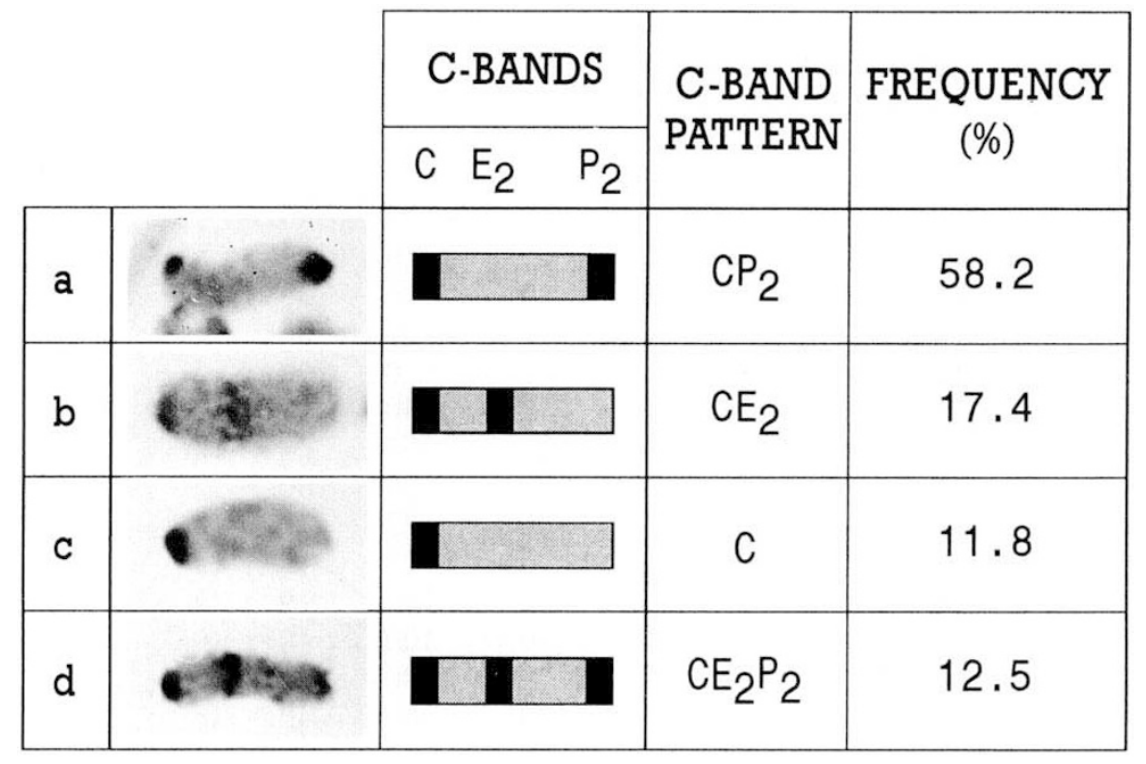

Fig. $1 \mathrm{X}$ chromosome $\mathrm{C}$-banding patterns found in the contact zone at the western end of the Pyrenees. Purelike patterns, Chorthippus parallelus parallelus (a) and Chorthippus parallelus erythropus (b). Recombinant patterns found only within the contact zone $(\mathrm{c}, \mathrm{d})$.
The two recombinant $\mathrm{C}$-banding patterns $(\mathrm{C}$ and $\mathrm{CE}_{2} \mathrm{P}_{2}$ ) appear only within the contact zone (Fig. 2c). Populations at the edge of the contact zone show a low frequency of these patterns whereas they are much more common in the centre of the $\mathrm{HZ}$ (up to 75 per cent).

\section{NOR expression}

NOR activity, as revealed by silver staining, was studied in zygotene meiocytes from adult males because at this stage previous rDNA activity can be seen as well-organized nucleoli. $C p p$ shows two active NORs on autosomes $\mathrm{L}_{2}$ and $\mathrm{L}_{3}$ and another on the sex chromosome ( $2 \mathrm{~A}+\mathrm{X}$ type cells) (Fig. 3a). Cpe lacks the $\mathrm{X}$ chromosome active NOR and so only shows the two autosomal ones (2A type cells) (Fig. 3b). Pure individuals have a low frequency (about 5 per cent) of cells with variant NOR activity. The contact zone is characterized by the coexistence of both types of individuals within a single population. Moreover, individuals are found which contain the two types of nucleolar expression in cells from the same cysts (Fig. 3c).

Individuals belonging to populations from the northeast of the zone studied were $C p p$-like $(2 \mathrm{~A}+\mathrm{X}$ type meiocytes) whereas those from the south-west were Cpe-like (2A type meiocytes) (Fig. 4a). This nucleolar variation could be quantified within each population as the percentage of cells which express the NOR associated with the sex chromosome. Frequencies and the shape of the cline are given in Table 1 and Fig. 4(b), respectively. Values for the width and centre of the cline obtained using the GENSTAT nonlinear regression model are shown in Table 2 . Fitted values could not be obtained for the limited sampling area (marked in Fig. 2a), as for the C-bands, because this area includes no pure $C p p$-like samples.

\section{Discussion}

\section{$X$ chromosome variants}

Four different $\mathrm{X}$ chromosome C-banding patterns have been found in the samples analysed. Two of them $\left(\mathrm{CP}_{2}\right.$ and $\left.\mathrm{CE}_{2}\right)$ are similar to those present in the pure subspecies whereas the other two $\left(\mathrm{C}\right.$ and $\left.\mathrm{CE}_{2} \mathrm{P}_{2}\right)$ are only found within the contact zone. The origin of the latter can be simply explained by recombination between the two pure forms. In a recombination event between $\mathrm{CP}_{2}$ and $\mathrm{CE}_{2}$ chromosomes, any chiasma formed between $E_{2}$ and $P_{2}$ bands gives rise to chromosomes containing either only the centromeric C-band (C pattern) or the three bands $\left(\mathrm{CE}_{2} \mathrm{P}_{2}\right.$ pattern $)$. This recombination phenomenon seems to be common within the contact zone analysed here; 24.3 per cent of the individuals studied presented recombinant $\mathrm{X}$-chromosomes (Fig. 1).

An additional heterochromatic band has been found on the $\mathrm{X}$ chromosome $\left(\mathrm{E}_{3}\right)$ in another contact zone in the Pyrenees, the Col de Portalet (L. Serrano et al., unpublished data). This band could have originated from unequal crossing-over events between two $\mathrm{X}$ chromosomes containing the $\mathrm{E}_{2}$ band so that a sex chromosome without interstitial bands and another one with two such bands $\left(E_{2}\right.$ and $\left.E_{3}\right)$ would be gener- 

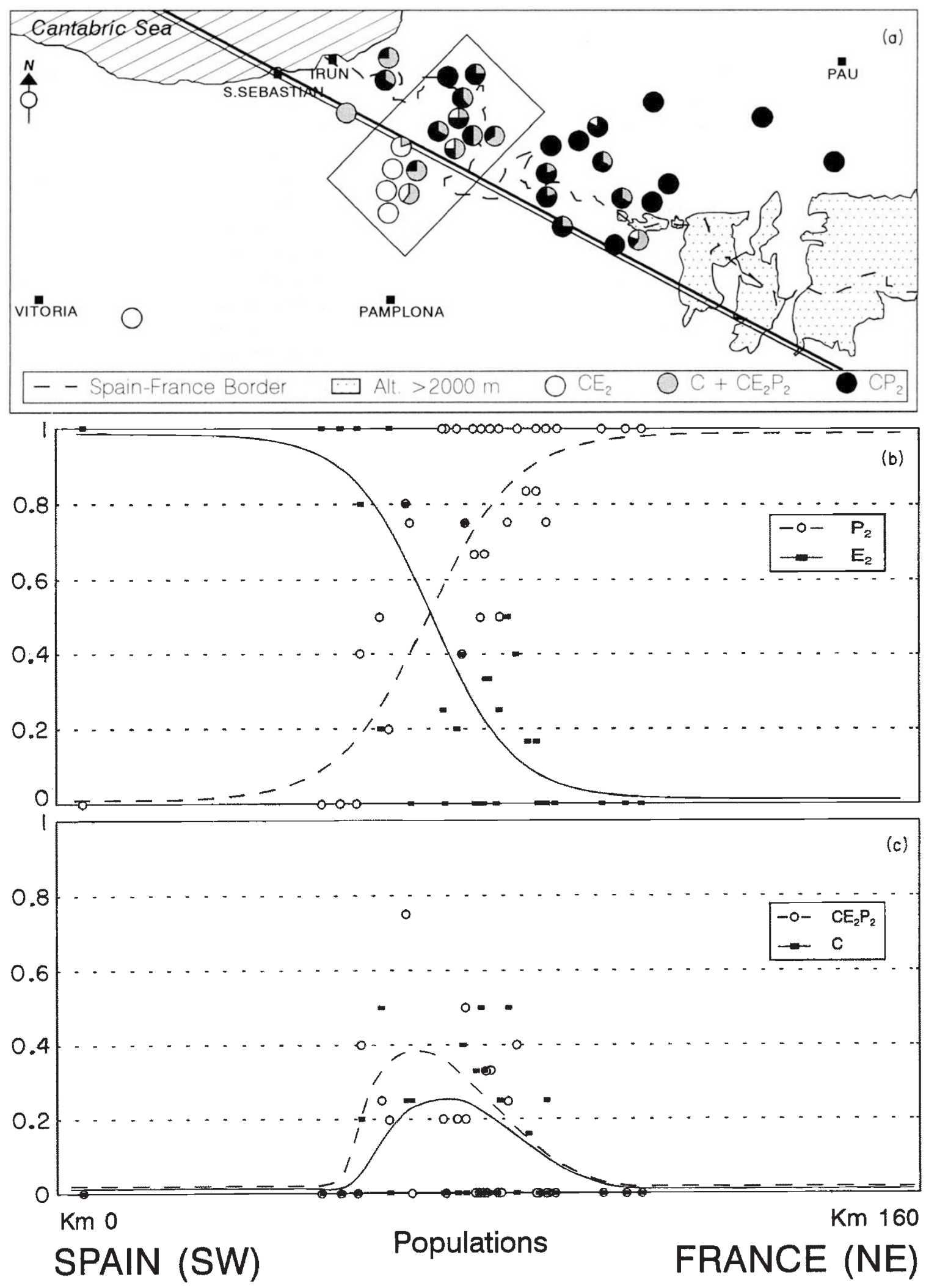

Fig. 2 Distribution of $X$ chromosome $C$-banding markers across the contact zone. (a) Map of the sampled zone. Pies show the ratio of patterns in each sampling site. Centres of the clines for the $P_{2}$ band (thin line) and the $E_{2}$ band (thick line) are shown. The best-sampled region of 14 populations is marked with a rectangle. (b) Clines for the $P_{2}$ and $E_{2} C$-bands. Fitted clines were obtained using the following function: $y=(1+\tanh (2(x-$ centre $) /$ width $)) / 2$. (c) Plots for the recombinant patterns $\mathrm{CE}_{2} \mathrm{P}_{2}$ and $\mathrm{C}$. 
ated. This band has only been found in hybrid populations of Col de Portalet and is absent from $\mathrm{Col}$ de la Quillane, a transect in Col de Somport (unpublished data) and the contact zone considered here. As this band is very common in the Col de

Table 2 Centres and widths of the clines for the chromosome markers analysed for the complete data set and the best-sampled region marked in Fig. 2(a). Centres are expressed in kilometres from the southernmost population ROI (Roitegui, Navarra)

\begin{tabular}{lcl}
\hline & Centre & Width \\
\hline Complete data set & & \\
$\mathrm{P}_{2}$ & $66.06(1.44)$ & $36.47(3.92)$ \\
$\mathrm{E}_{2}$ & $66.93(1.31)$ & $33.02(3.45)$ \\
$\mathrm{X}$-NOR & $82.04(2.04)$ & $55.82(11.08)$ \\
Best sampled region & & \\
$\mathrm{P}_{2}$ & $65.83(4.82)$ & $41.53(1.57)$ \\
$\mathrm{E}_{2}$ & $62.55(4.05)$ & $37.94(1.61)$ \\
\hline
\end{tabular}

Standard errors (see GENSTAT 5, 1987) are shown in parentheses.
Portalet ( 27 per cent of individuals), it does not seem that sampling error can be the reason for its absence in our samples. The origin of $E_{3}$ would appear to be a rare event within the whole $\mathrm{HZ}$ along the Pyrenees. In fact, only 98 of 4000 male individuals studied through the $\mathrm{HZ}$ had such a band and all of these were from the Col de Portalet contact zone. Furthermore, the data obtained from the Col de Portalet populations indicate that once this mutation has been integrated in a hybrid genome, it can increase in frequency, probably because mispairing between homologous chromosomes inhibits chromosome recombination. This variant would then be inherited unaltered from one generation to another.

The presence of chromosome variants, morphological aberrations or the so-called 'rare alleles' within HZs has been reported in several studies and their frequencies can, in certain situations, be notably high (Barton et al., 1983; Woodruff, 1989). The present results show that these mutations do not apply for all the contact zones within a particular HZ, so their presence might be dependent on random processes that give the opportunity for establishment in a single population and spread in subsequent generations. In any case, the fact that pure-like and simple recombi-

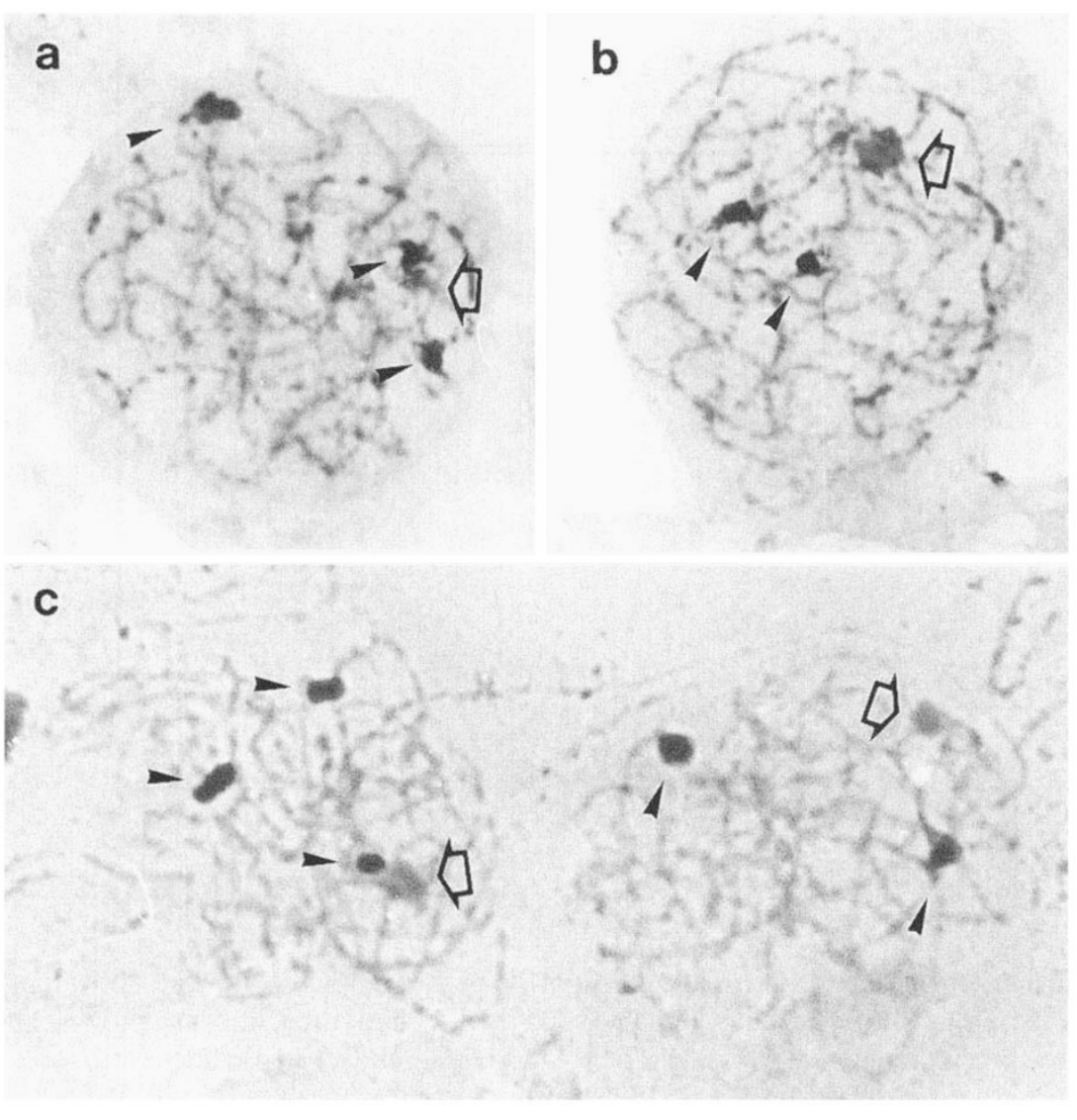

Fig. 3 Silver- stained pachytene meiocytes showing NOR activity. (a) Chorthippus parallelus parallelus has three active NORs (arrowheads), two on autosomes $\mathrm{L}_{2}$ and $\mathrm{L}_{3}$ and a third on the $\mathrm{X}$ chromosome (open arrow). $2 \mathrm{~A}+\mathrm{X}$ type cells. (b) Chorthippus parallelus erythropus has only the two autosomal active NORs. 2A type cells. (c) Hybrid individuals show both types of cells. 

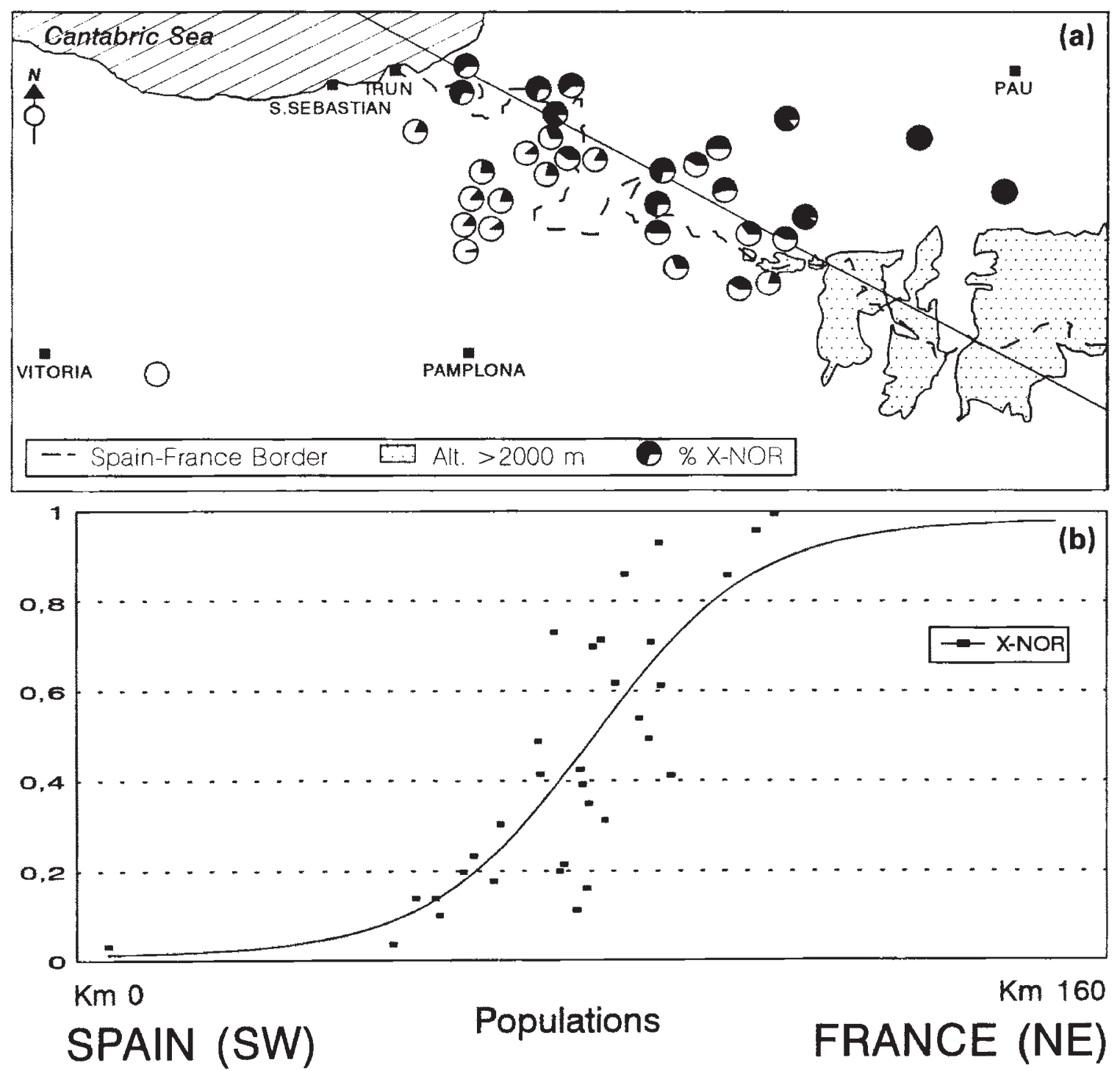

Fig. 4 X-NOR activity across the contact zone. (a) Map of the sampled zone. Pies show the ratio of cells with an active X-NOR in each sampling site. The centre of the cline for the X-NOR activity (thin line) is shown. (b) Cline for the X-NOR activity. Fitted cline was obtained as in Fig. 2(b).

nant forms appear in this region, in a similar fashion to that reported in other cols, fits with the general assumption of the origin of this $\mathrm{HZ}$ as a product of a secondary contact occurring all along the Pyrenees.

\section{Position and width of the clines}

The analysis of the shape of a cline may yield information about the role of the characters involved. For instance, the width of a cline (measured as $w=m_{\max }^{-1}$, where $w$ and $m_{\max }$ are the width and maximum slope of the cline, respectively (Bazykin, 1969)), is determined by dispersal and selection and so can give information on the intensity of selection acting on the character $\left(w=\left(8 \sigma^{2} / s\right)^{-1 / 2}\right.$, where $w, \sigma$ and $s$ are estimates of width, dispersal and selection, respectively) (Barton \& Hewitt, 1989). Within a $\mathrm{HZ}$ under particular dispersal conditions a neutral character would have a wider cline whereas a narrower cline indicates that there is selection against the character involved. A cline may be centred within the contact zone or may be displaced towards either pure side. Selection by the environment or the background genome may also influence the position of a character cline. An advantageous allele or block of alleles may spread and replace a disadvantaged one so that its cline is displaced towards the 
other race's range. Clines of the same width are said to be concordant and clines centred at the same point are said to be coincident (Hewitt, 1988).

Variation among localities in the width of clines is a common feature in hybrid zones (Butlin et al., 1991). This variation has been found in hybrid zones of Bombina (Szymura \& Barton, 1986), Caledia (Marchant et al., 1988), Heliconius (Mallet \& Barton, 1989), Mus (Vanlerberghe et al., 1988), Podisma (Nichols \& Hewitt, 1986) and Chorthippus (Hewitt, 1990). The width of the clines at the contact zone studied here is larger than for comparable characters from other Pyrenean contact zones such as the Cols de Portalet and la Quillane (Fig. 5) which themselves show differences in the width of their clines. Comparisons of width and selection within a contact zone can easily be made. However, comparisons between different contact zones are more difficult because factors such as interdigitation may be modulating the widths differentially. The most likely cause of wider clines in the western end contact zone is the physical geography and habitat structure. The mountain ridge in the western end contact zone is lower and smoother than at the Cols de Portalet and Quillane and should permit greater dispersal of the grasshoppers. This will result in a higher rate of immigration of alleles from both sides in this contact zone and that would make the clines wider. The interdigitation of valleys and ridges may also be the cause of the higher deviance of the points from the fitted clines at the western end of the Pyrenees compared with those at the cols.

Interdigitation during the process of colonization following the last glaciation could have generated clines that are wider than can be explained purely by

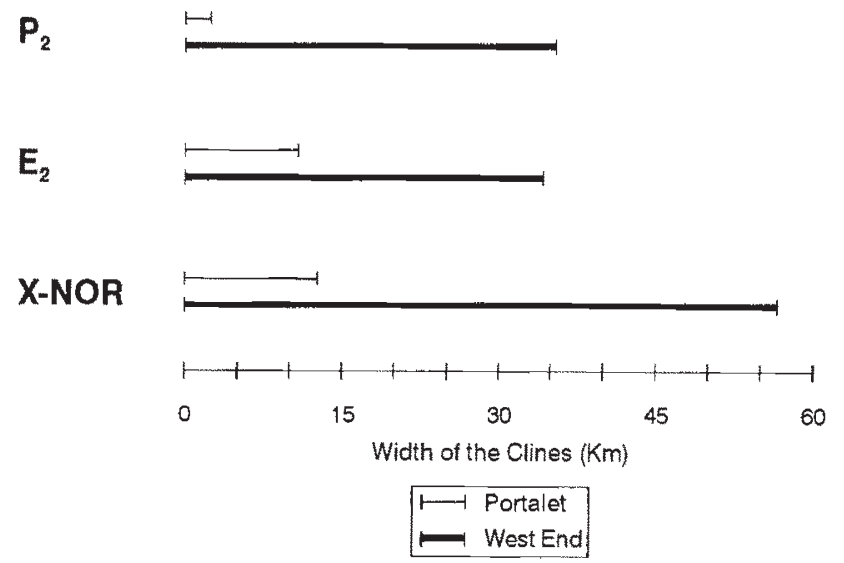

Fig. 5 Comparisons of cline widths for the different markers studied between the Col de Portalet and the western Pyrenees contact zones. diffusion of neutral alleles (Nichols \& Hewitt, 1994). In the case of $C p$, where dispersal in an occupied habitat is in the region of $30 \mathrm{~m}$ per generation (Virdee \& Hewitt, 1990), a diffusion process suggests a cline width of $2-3 \mathrm{~km}$ given some 9000 generations since contact (Endler, 1977). This is insufficient to account for the cline widths seen at the Col de Portalet, let alone the wider clines observed in these data. However, spread into unoccupied territory must involve longerdistance dispersal (Hewitt, 1989) and the possibility of broad intermingling where two expanding populations meet. The broad distribution of suitable habitat in the western Pyrenees may have allowed this process to

\section{COL DE PORTALET}

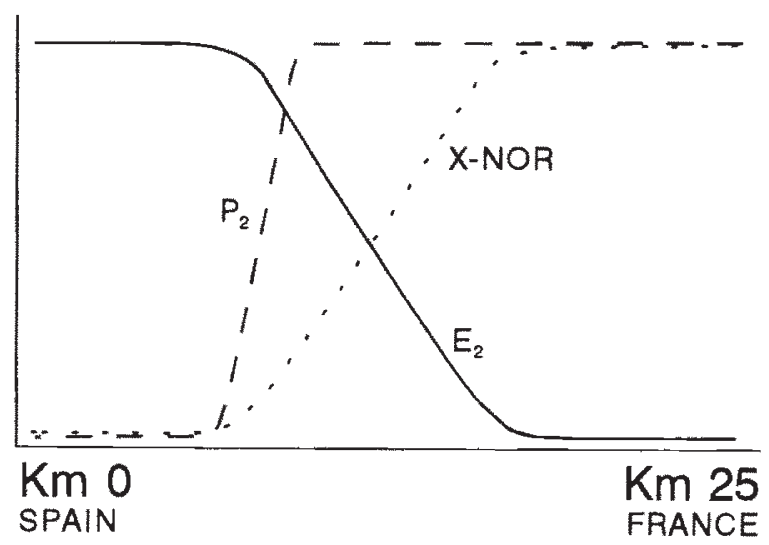

\section{WESTERN PYRENEES}

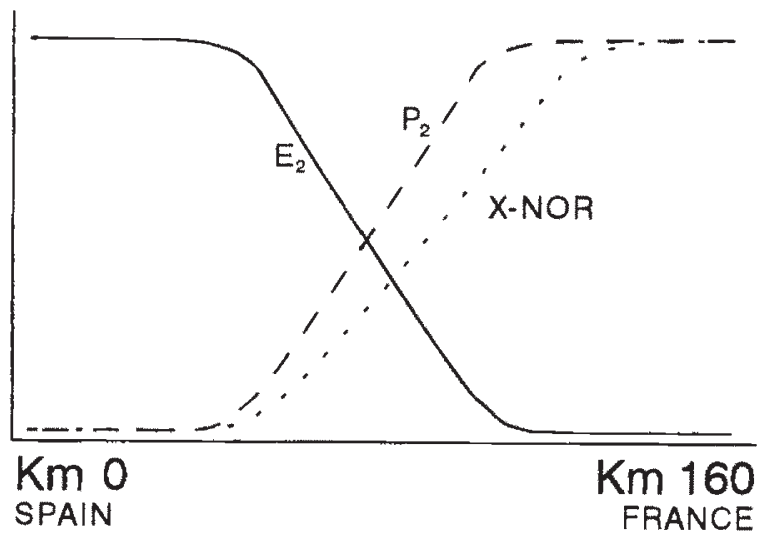

Fig. 6 Clines for the characters analysed from the contact zones at the western end of the Pyrenees and at Col de Portalet. Note the considerable difference in width as well as some differences in the features of the clines between both contact zones. 
operate more freely than in the narrow valleys of the Portalet area, producing wider clines. In these circumstances, precise coincidence of cline centres would not be expected.

It has been suggested (Hewitt, 1989; Nichols \& Hewitt, 1994), on the basis of cline widths in other localities, that the NOR expression differences between subspecies are likely to result in selection against hybrids. The wide NOR clines observed here do not support this point of view. The $\mathrm{P}_{2}$ band also offers a contrast between localities. It shows a narrow cline, potentially indicative of selection, at $\mathrm{Col} \mathrm{de}$ Portalet but a wide cline in these samples. The situation here is complicated by the presence of the $E_{3}$ band at Portalet. The distribution of this band appears to be related to a displacement of the $\mathrm{P}_{2}$ cline to the south as well as to the steepening of its cline (Fig. 6).

Clearly, further sampling would provide better estimates of the positions and widths of the clines in the western Pyrenees. More localities would provide better information than larger samples (the reason for the relatively small individual sample sizes here). However, the data available here are sufficient to say that the cline centres approximate to the watershed as expected and that the clines are substantially different in width from those at other localities. These conclusions hold whether the whole data set is analysed or attention is restricted to the best-sampled central area (Table 2).

\section{Acknowledgements}

We acknowledge Dr José Luis Bella, Dr Carlos García de la Vega, Dr Philip Mason and Dr Joaquina de la Torre for useful comments of the manuscript and $\mathbf{J}$. Martín for help with computing. The UAM grasshopper group, including Altea Gosálvez, helped with the field work. This work was supported by grants from EEC (SC1-0127C) and CICYT (PB90-1092), Spain.

\section{References}

BARTON, N. H., HALLIDAY, R. B. AND HEWITT, G. M. 1983. Rare electrophoretic variants in a hybrid zone. Heredity, 50, 139-146.

BARTON, N. H. AND HEWITT, G. M. 1989. Adaptation, speciation and hybrid zones. Nature, 341, 497-503.

BAZYKIN, A. D. 1969. Hypothetical mechanisms of speciation. Evolution, 23, 685-687.

BELLA, J. L., BUTLIN, R. K., FERRIS, C. AND HEWTT, G. M. 1992. Asymmetrical homogamy and unequal sex ratio from reciprocal mating-order crosses between Chorthippus parallelus subspecies. Heredity, 68, 345-352.

Bella, J. L., hewitT, G. M. AND GosÁlveZ, J. 1990. Meiotic imbalance in laboratory-produced hybrid males of
Chorthippus parallelus parallelus and Chorthippus parallelus erythropus. Genet. Res., 56, 43-48.

BELlA, J. L., SERRANO, L., HEWiTT, G. M. AND gOSÁlVEZ, J. 1993. Heterochromatin heterogeneity and rapid divergence of the sex chromosomes in Chorthippus parallelus parallelus and C.p. erythropus (Orthoptera). Genome, 36, 542-547.

BUTLIN, R. K. AND HEwITT, G. M. 1985a. A hybrid zone between Chorthippus parallelus parallelus and Chorthippus parallelus erythropus (Orthoptera: Acrididae): morphological and electrophoretical characters. Biol. J. Linn. Soc., 26, 269-285.

BUTLIN, R. K. AND HEWTT, G. M. 1985 b. A hybrid zone between Chorthippus parallelus parallelus and Chorthippus parallelus erythropus (Orthoptera: Acrididae): behavioural characters. Biol. J. Linn. Soc., 26, 287-299.

BUTLIN, R. K., RITCHIE, M. G. AND HEWITT, G. M. 1991. Comparisons among morphological characters and between localities in the Chorthippus parallelus hybrid zone (Orthoptera: Acrididae). Phil. Trans. R. Soc. B, 334, 297-308.

ENDLER, J. A. 1977. Geographic Variation, Speciation and Clines. Princeton University Press, Princeton.

FABER, A. 1958. Chorthippus erythropus n. sp. ein nächster Verwandter de Germanien Grasschercke (Ch. longicornis Latv.). Stuttgarter Beiträge zur Naturkunde, 16, 1-8.

GENSTAT 5. 1987. genstat 5. Reference Manual. Clarendon Press, Oxford.

GOSÁLVEZ, J., LOPEZ-FERNÁNDEZ, C., BELLA, J. L., BUTLIN, R. K. AND HEWTT, G. M. 1988. A hybrid zone between Chorthippus parallelus parallelus and Chorthippus parallelus erythropus (Orthoptera: Acrididae): chromosomal differentiation. Genome, 30, 656-663.

HEWITT, G. M. 1988. Hybrid zones: natural laboratories for evolutionary studies. Trends Ecol. Evol., 3, 158-167.

HEWIT, G. M. 1989. The subdivision of species by hybrid zones. In: Otte, D. and Endler, J. (eds) Speciation and its Consequences, pp. 85-109. Sinauer Associates, Sunderland, MA.

HEWITT, G. M. 1990. Divergence and speciation as viewed from an insect hybrid zone. Can. J. Zool., 68, 1701-1715.

HEWITT, G. M. 1993. After the ice: parallelus meets erythropus in the Pyrenees. In: Harrison, R. G. (ed.) Hybrid Zones and the Evolutionary Process, pp. 140-164. Oxford University Press, Oxford.

HEWITT, G. M., GOSÁLVEZ, J., LOPEZ-FERNÁNDEZ, C., RITCHIE, M. G., Nichols, W. AND BUTLIN, R. K. 1988. Differences in the nucleolar organisers, sex chromosomes and Haldane's rule in a hybrid zone. In: Brandham, P. E. (ed.) Kew Chromosome Conference, vol. III, pp. 109-119. HMSO, London.

MALLET, J. AND BARTON, N. H. 1989. Strong natural selection in a warning-color hybrid zone. Evolution, 43, 421-431.

MARCHANT, A. D., ARNOLD, M. L. AND WILKINSON, P. 1988. Gene flow across a chromosomal tension zone. 1. Relicts of ancient hybridization. Heredity, 61, 321-328.

NICHOLS, R. A. AND HEWITT, G. M. 1986. Population structure and the shape of a chromosomal cline between two races of Podisma pedestris (Orthoptera: Acrididae). Biol. J. Linn. Soc., 29, 301-316. 
NICHOLS, R. A. AND HEWITT, G. M. 1994. The genetic consequences of long distance dispersal during colonization. Heredity, 72, 312-317.

REYNOLDS, w. J. 1980. A re-examination of the characters separating Chorthippus montanus and C. parallelus (Orthoptera: Acrididae). J. Nat. Hist., 14, 283-303.

RiTCHIE, M. G. 1990. Are differences in song responsible for assortative mating between subspecies of the grasshopper Chorthippus parallelus (Orthoptera: Acrididae)? Anim. Behav., 39, 685-691.

RITCHIE, M. G., BUTLIN, R. K. AND HEWITT, G. M. 1989. Assortative mating across a hybrid zone in Chorthippus parallelus (Orthoptera: Acrididae). J. Evol. Biol., 2, 339-352.

RITCHIE, M. G., BUTLIN, R. K. AND HEWITT, G. M. 1992. Fitness consequences of potential assortative mating inside and outside a hybrid zone in Chorthippus parallelus (Orthoptera: Acrididae): implications for reinforcement and sexual selection theory. Biol. J. Linn. Soc., 45, 219-234.

RUFAS, J. S. AND GOSAlvez, J. 1982. Development of silver stained structures during spermatogenesis of Schistocerca gregaria (Forsk) (Orthoptera: Acrididae). Caryologia, 35, 261-267.

SUMNER, A. T. 1972. A single technique for demonstrating centromeric heterochromatin. Exp. Cell. Res., 75, 304-306.

SZYMURA, J. M. AND BARTON, N. H. 1986. Genetic analysis of a hybrid zone between the fire-bellied toads, Bombina bombina and $B$. variegata, near Cracow in Southern Poland. Evolution, 40, 1141-1159.

VANLERBERGHE, F, BOURSOT, P., NIELSEN, J. T. AND BONHOMME, F 1988. A steep cline for mitochondrial DNA in Danish mice. Genet. Res., 52, 185-193.

VIRDEE, S. AND HEWITT, G. M. 1990. Ecological components of a hybrid zone in the grasshopper Chorthippus parallelus (Zetterstedt) (Orthoptera: Acrididae). Bol. San. Veg. Plagas, 20, 299-309.

woodRUFF, D. S. 1989. Genetic anomalies associated with Cerion hybrid zones: the origin and maintainance of the new electromorphic variants called hybrizymes. Biol. J. Linn. Soc., 36, 281-294. 